\title{
One-Dimensional $\mathrm{TiO}_{2}$-B Crystals Synthesised by Hydrothermal Process and Their Antibacterial Behaviour on Escherichia coli
}

\author{
Sergio León-Ríos, ${ }^{1}$ Rodrigo Espinoza González, ${ }^{2}$ Sandra Fuentes, ${ }^{3}$ Emigdio Chávez Ángel, ${ }^{4}$ \\ Alex Echeverría, ${ }^{5}$ Antonio E. Serrano, ${ }^{5}$ Cecilia S. Demergasso, ${ }^{5}$ and R. Antonio Zárate ${ }^{1}$ \\ ${ }^{1}$ Departamento de Física, Facultad de Ciencias, Universidad Católica del Norte, Casilla 1280, Antofagasta, Chile \\ ${ }^{2}$ Departamento de Ciencias de los Materiales, Facultad de Ciencias Físicas y Matemáticas, Universidad de Chile, \\ Avenida Tupper 2069, 8370451 Santiago, Chile \\ ${ }^{3}$ Departamento de Ciencias Farmacéuticas, Facultad de Ciencias, Universidad Católica del Norte, Casilla 1280, Antofagasta, Chile \\ ${ }^{4}$ Department of Physics, Johannes Gutenberg-University Mainz, Staudinger Weg 7, 55128 Mainz, Germany \\ ${ }^{5}$ Centro de Biotecnología, Universidad Católica del Norte, Casilla 1280, Antofagasta, Chile
}

Correspondence should be addressed to R. Antonio Zárate; rzarate@ucn.cl

Received 11 November 2015; Revised 22 March 2016; Accepted 30 March 2016

Academic Editor: Alexey P. Popov

Copyright (C) 2016 Sergio León-Ríos et al. This is an open access article distributed under the Creative Commons Attribution License, which permits unrestricted use, distribution, and reproduction in any medium, provided the original work is properly cited.

We have successfully synthesised one-dimensional single crystals of monoclinic phase titanium dioxide nanostructures $\left(\mathrm{TiO}_{2}-\right.$ B), prepared by a hydrothermal process. Morphological characterization was carried out by atomic force and scanning and transmission electron microscopy techniques. In order to study the crystalline structure, samples were calcined at $500^{\circ} \mathrm{C}$ in an air-filled chamber. X-ray diffraction results indicated that as-prepared samples presented diffraction patterns of hydrate hydrogen titanate and those calcined at $500^{\circ} \mathrm{C}$ exhibited the $\mathrm{TiO}_{2}-\mathrm{B}$ and anatase phases, confirmed by Raman spectroscopy. Scanning electron microscopy results showed that the one-dimensional nanostructures had high contrast and uniform widths for those synthesised and calcined, indicating the formation of a phase of monocrystals. Besides, a proof of the antibacterial effect was carried out of the monoclinic phase of $\mathrm{TiO}_{2}-\mathrm{B}$ on Escherichia coli pure cultures, where the viability of the bacterium decreases in presence of $\mathrm{TiO}_{2}-\mathrm{B}$ nanostructures plus UV illumination. Monocrystals did not change after photocatalytic tests, suggesting a possible application as long-term antibacterial protection.

\section{Background}

Titanium dioxide $\left(\mathrm{TiO}_{2}\right)$ is a polymorph ceramic material with well-known stable phases called anatase and rutile. Other metastable phases are brookite and monoclinic. The monoclinic phase of titanium dioxide is usually called $\mathrm{TiO}_{2}$ $\mathrm{B}$, exhibiting more open-structure than rutile, anatase, and brookite $[1,2]$. This $\mathrm{TiO}_{2}-\mathrm{B}$ has been synthesised by three different methods. Marchand et al. in 1980 [3] used hydrolysis of $\mathrm{K}_{2} \mathrm{Ti}_{4} \mathrm{O}_{9}$ followed by heating. A second method introduced modifications to the Marchand method with $\mathrm{K}_{2} \mathrm{TiF}_{6}$ solution instead of $\mathrm{K}_{2} \mathrm{Ti}_{4} \mathrm{O}_{9}$ and mixing with ammonium hydroxide solution in order to obtain metastable compounds [4]. Recently, hydrothermal reaction of titania in a concentrated $\mathrm{NaOH}$ solution with moderate heating has been reported [5].
Research of new antibacterial materials is a general interest based on the rise of multiresistant pathogens. In this sense, antibacterial effects of $\mathrm{TiO}_{2}$ by photocatalysis have been reviewed [6], driven by the production of reactive species against microorganisms [7]. This reaction occurs when particles are illuminated by light with energy higher than its band gap [8]. Electrons in $\mathrm{TiO}_{2}$ jump from the valence band to the conduction band, and negative charges $\left(\mathrm{e}^{-}\right)$with the positive electric-hole $\left(\mathrm{h}^{+}\right)$pairs are formed on the surface of the photocatalyst. Absorbed water molecules are oxidized by the positive electric-holes $\left(\mathrm{h}^{+}\right)$, forming hydroxyl free radicals, with a high oxidation power [9]. Moreover, negative charges react with the oxygen in water, generating superoxide radicals, producing ion homeostasis deregulation, coenzyme-independent respiration, and cell wall structure disruption [10-12]. 
By particle-size reduction at nanoscale level of $\mathrm{TiO}_{2}$ crystals, improvements in the antibacterial properties of spherical particles $(320 \mathrm{~nm})$ in Escherichia coli cultures have been demonstrated [13]. To contribute with the above, this work reports the synthesis of one-dimensional $\mathrm{TiO}_{2}-\mathrm{B}(1 \mathrm{D}$ $\left.\mathrm{TiO}_{2}-\mathrm{B}\right)$ nanostructures including wires and platelets shapes [14] by one-step hydrothermal reaction and their antibacterial property, which is due to photocatalysis. Samples were calcined and characterized by a battery of techniques, such as X-ray diffraction (XRD), atomic force microscopy (AFM), Raman spectroscopy, field electron gun scanning electron microscopy (FEG-SEM), and transmission electron microscopy (TEM). In this work, $1 \mathrm{D}-\mathrm{TiO}_{2}-\mathrm{B}$ antibacterial activity was compared to spherical anatase nanoparticles, where the viability of Escherichia coli cultures exposed to 1D$\mathrm{TiO}_{2}$-B plus ultraviolet radiation was reduced. Furthermore, Raman analysis and light absorption test were run to confirm that structural characteristics do not change after antibacterial experiences.

\section{Methods}

Synthesis of hydrogen titanate hydrated was performed hydrothermally in a Teflon ${ }^{\circledR}$ beaker containing $25 \mathrm{~mL} \mathrm{NaOH}$ (Aldrich, 99.99\%) at a concentration of $10 \mathrm{M}$, placed in a sealed reactor together with $0.21 \mathrm{~g}$ of $\mathrm{TiO}_{2}$ in the anatase phase (Aldrich, 99.8\%). The resulting solution was stirred for $1 \mathrm{~h}$ at room temperature. The mixture was then heated at $130^{\circ} \mathrm{C}$ and treated for 6 or 8 days. The treated powders were washed with $0.1 \mathrm{M} \mathrm{HCl}$ (Sigma) aqueous solution and distilled water and were subsequently separated from the solution by centrifugation. This procedure was repeated until the washing water showed $\mathrm{pH}$ about 7 . Powders were calcined at $500^{\circ} \mathrm{C}$ for an evolution of crystal structure study.

For morphology analyses, samples were ultrasonically dispersed in isopropanol and deposited onto a grid and examined with a Field Emission Gun Scanning Electron Microscope (FEG-SEM) model JSM-6330F (Jeol, Japan) and with an Atomic Force Microscope (AFM), alpha 300A (WiTec, Germany). By D5000 powder diffractometer with nonmonochromatized $\mathrm{CuK} \alpha$ radiation $(40 \mathrm{kV}, 30 \mathrm{~mA})$ (Siemens, Germany), 1D nanostructures were characterized. Also, using $514.5 \mathrm{~nm} \mathrm{Ar}$ and $632.8 \mathrm{~nm} \mathrm{He}-\mathrm{Ne}$ lasers by a CRM 200 Confocal Raman Microscopy (WiTec, Germany), vibrational Raman spectra were collected. Energy dispersive X-ray (EDX) spectroscopy spectra were acquired with a Low Vacuum Scanning Electron Microscope (LV-SEM) model JSM-5900LV equipped with X-ray Microanalysis (Jeol, Japan). High-resolution images were obtained using a TEM model 3010 operating at $300 \mathrm{kV}$ with a point resolution of $0.17 \mathrm{~nm}$, which is equipped with EDX and selected area electron diffraction (SAED) (Jeol, Japan). Diffuse reflectance was obtained with a lambda $20 \mathrm{UV}-\mathrm{Vis}$ spectrometer (Perkin Elmer, USA).

For antibacterial tests, Escherichia coli ATCC 25922 ${ }^{\circledR}$ cultures were grown aerobically in $10 \mathrm{~mL}$ glass test tube containing $9 \mathrm{~mL}$ of liquid broth and $1 \mathrm{~mL}$ of inoculum containing $1 \times 10^{6}$ cells at $35^{\circ} \mathrm{C}$ for $20 \mathrm{~h}$. Loss of viability was studied using $10 \mathrm{mg}$ of $\mathrm{TiO}_{2}-\mathrm{B}$ and anatase per sample.
The final cell concentration was determined by a viable cell count procedure using colony forming units (CFU) counting technique. A tube containing $E$. coli without nanostructures was irradiated as control. Also dark test was carried out. In order to perform photocatalytic experiment, plates containing $9 \mathrm{~mL}$ of $\mathrm{NaCl} 0.9 \%$ and $1 \mathrm{~mL}$ of cell solution were prepared. Following that, test plates were UV-illuminated using a HL 200 HybriLinker oven with wavelength $\lambda=$ $254 \mathrm{~nm}$ and $120000 \mu \mathrm{J}$ (UVP, USA). $10 \mu \mathrm{L}$ of sample was taken in periodic intervals $(0,10,20,30$, and $40 \mathrm{~min})$ in triplicate and then inoculated into plates containing tryptone soy agar and incubated for $16 \mathrm{~h}$ at $35^{\circ} \mathrm{C}$. In order to analyse the loss of viability, CFU count was performed. Finally, Raman analysis tests were run to demonstrate that main properties of $\mathrm{TiO}_{2}-\mathrm{B}$ nanostructures did not change after antibacterial test. One-dimensional nanostructures were washed with $0.5 \mathrm{M} \mathrm{KOH}$ and deionized water and then dried for $6 \mathrm{~h}$ at room temperature before the spectroscopic analysis.

\section{Results and Discussion}

3.1. Morphology and Compositional Analysis. Based on similar synthesis of $\mathrm{TiO}_{2}-\mathrm{B}$ nanofibers, nanowires, and nanotubes conducted by hydrothermal processes before $[15,16]$, morphology of the samples using FEG-SEM and AFM analyses was performed. The shapes of the starting anatase material were particles between $50 \mathrm{~nm}$ and $300 \mathrm{~nm}$ in diameter (Figure 1(a)). After hydrothermal treatment at $130^{\circ} \mathrm{C}$ for 8 days, anatase particles were transformed into platelet-like mineral, as shown in Figures 1(b) and 1(c), with a length of 0.2 to 1.2 micrometres and an average thickness of $100 \mathrm{~nm}$ (Figure $1(\mathrm{~d})$ ). Other samples were obtained after a shorter hydrothermal treatment at $130^{\circ} \mathrm{C}$ for 6 days. The anatase nanoparticles were completely transformed into wire-like shapes, the hydrothermal process time being a variable that can mould the final morphology of the 1D structures (Figures 1(e) and 1(f)).

Compositional analysis was carried out using energy dispersive X-ray spectroscopy, attached to a high-resolution transmission electron microscope (TEM). Spectra of asprepared and calcined samples presented $\mathrm{Ti}, \mathrm{O}, \mathrm{Cu}$, and $\mathrm{Al}$, as shown in Figure 2(a). Copper came from the sample holder and aluminium from the calcination process. The $\mathrm{O} K \alpha$ and $\mathrm{Ti} \mathrm{K} \alpha$ peaks are observed at 0.520 and $4.51 \mathrm{keV}$. The chemical composition of the $\mathrm{TiO}_{2}$ platelets was approximately 64.9 at $\%$ $\mathrm{O}$ and 35.1 at $\% \mathrm{Ti}$. These values are near the ideal stoichiometry of the $\mathrm{TiO}_{2}$ compound, which is around 66 at $\% \mathrm{O}$ and 33 at $\% \mathrm{Ti}$. Element weight and atomic percentage of $\mathrm{TiO}_{2}$ bulk sample are shown in Figure 2(b). Considering experimental data, theoretical atomic weight, and the low copper presence due to the sample holder, the calculated composition of the sample was $\mathrm{Ti}(1) \mathrm{O}(1.73) \mathrm{Al}(0.07) \mathrm{Cu}(0.40)$.

\subsection{Structural Analysis by Transmission Electron Microscopy.} To study the architectural properties of $1 \mathrm{D}-\mathrm{TiO}_{2}-\mathrm{B}$ materials, structural analysis was performed by high-resolution microscopy. Figure 3(a) shows a low magnification TEM bright field image without annealing at $500^{\circ} \mathrm{C}$ in an air-filled 


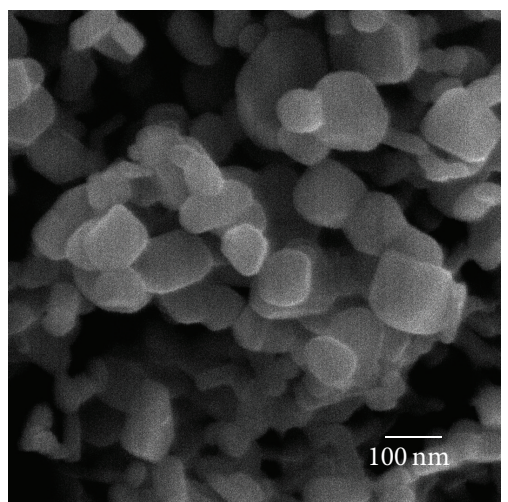

(a)


(d)



(b)

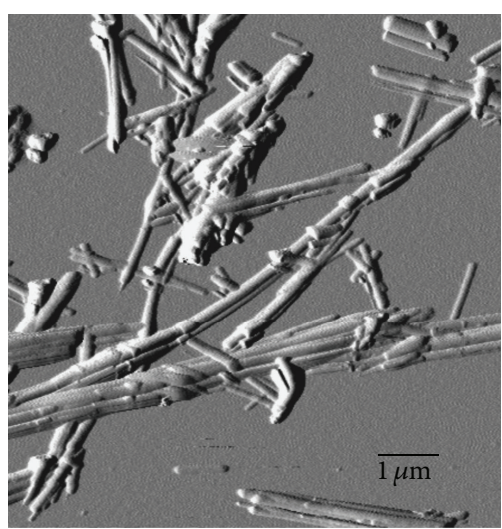

(e)

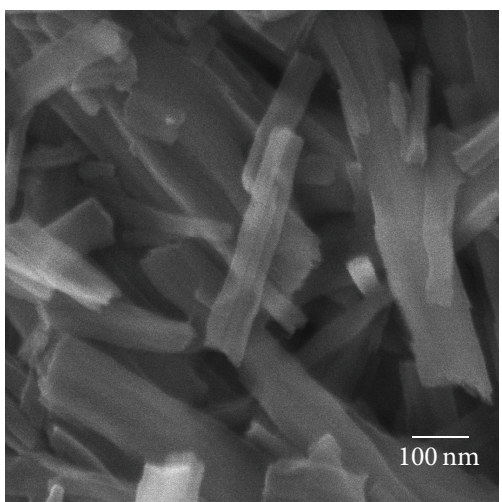

(c)

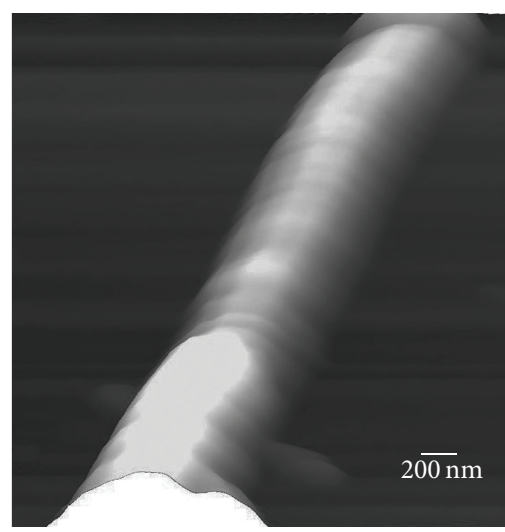

(f)

Figure 1: Morphology of one-dimensional $\mathrm{TiO}_{2}$ nanostructures synthesised by hydrothermal process at $130^{\circ} \mathrm{C}$ in a $10 \mathrm{M} \mathrm{NaOH}$ solution for 6-8 days of reaction: (a) Starting material, anatase phase nanoparticles. Platelet-like shapes (b) at low magnification and (c) at high resolution after 8 days of hydrothermal synthesis, images collected at $5.0 \mathrm{kV}$. (d) Histograms of frequency distribution data of length and thickness of the nanostructures. (e) Low-resolution amplitude atomic force microscopy (AFM) scan image of one-dimensional $\mathrm{TiO}_{2}$ wire-like shape and high-resolution topography (f) scanned after 6 days of hydrothermal process synthesis.

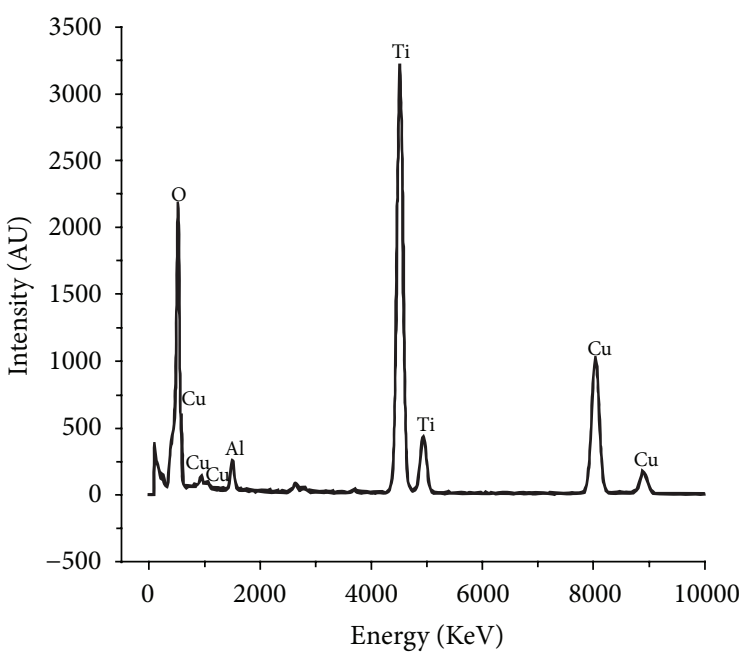

(a)

\begin{tabular}{|c|c|c|}
\hline Element & Weight \% & $\overline{\text { Atomic } \%}$ \\
\hline$\overline{\mathrm{O}(\mathrm{K})}$ & 27.67 & 55.13 \\
\hline $\mathrm{Al}(\mathrm{K})$ & 1.80 & 2.12 \\
\hline $\operatorname{Ti}(\mathrm{K})$ & 44.86 & 29.86 \\
\hline $\mathrm{Cu}(\mathrm{K})$ & 25.65 & 12.87 \\
\hline Element & \multicolumn{2}{|c|}{ Atomic weight $(\mathrm{g} / \mathrm{mol})$} \\
\hline $\mathrm{Ti}$ & \multicolumn{2}{|c|}{47.88} \\
\hline $\mathrm{O}$ & \multicolumn{2}{|c|}{$\begin{array}{l}15.00 \\
15.99\end{array}$} \\
\hline
\end{tabular}

(b)

FIgURE 2: Compositional analysis of synthesised one-dimensional $\mathrm{TiO}_{2}-\mathrm{B}$ nanostructures. (a) Energy dispersive $\mathrm{X}$-ray spectroscopy spectrum of $\mathrm{TiO}_{2}-\mathrm{B}$ platelets was obtained by hydrothermal process at $130^{\circ} \mathrm{C}$ for 8 days of reaction. (b) Element weight and atomic percentage of the sample. 


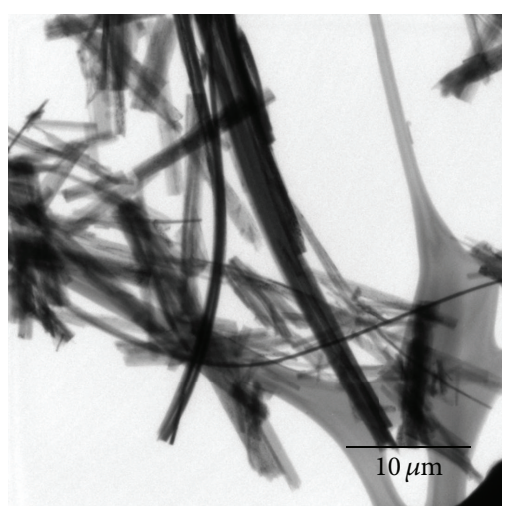

(a)

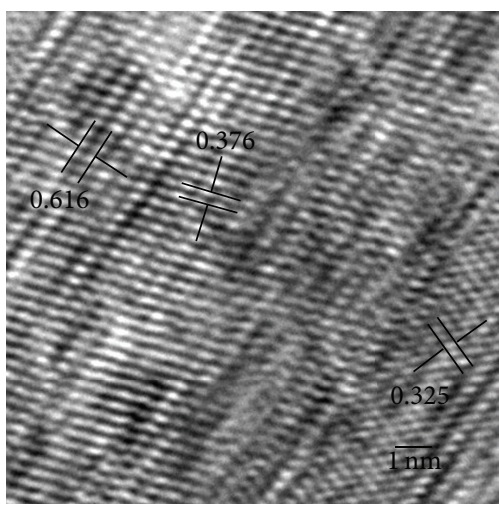

(d)

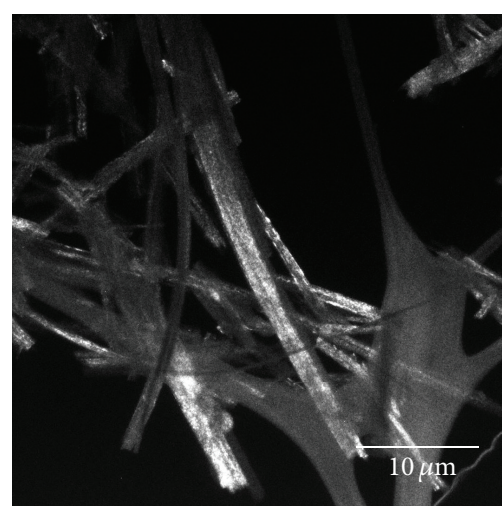

(b)

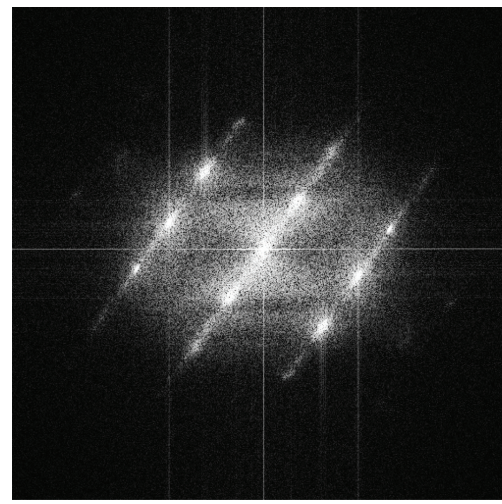

(e)

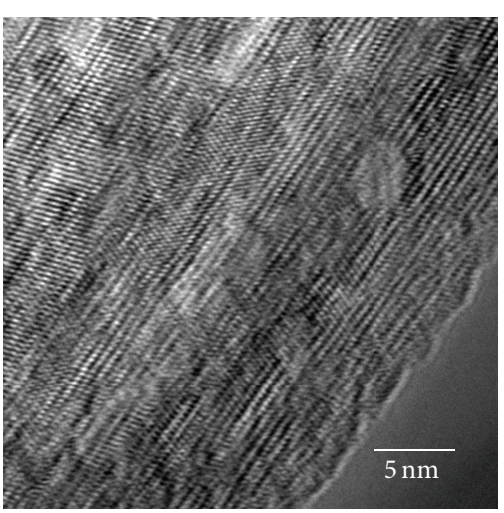

(c)

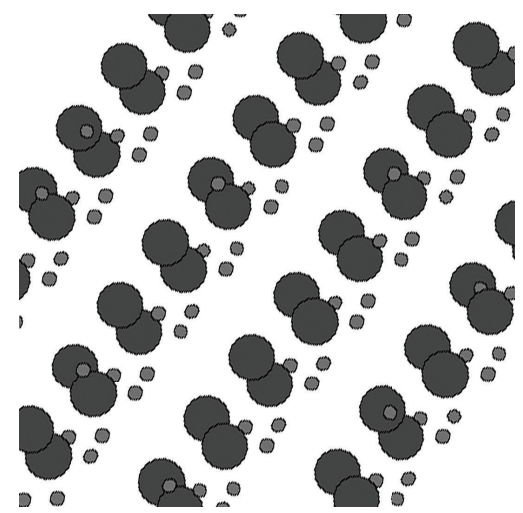

(f)

FIGURE 3: HR-TEM and SAED field analysis of synthesised $\mathrm{TiO}_{2}-\mathrm{B}$ nanostructures. (a) Low magnification bright field image of sample treated at $130^{\circ} \mathrm{C}$ for 8 days. (b) Dark field oriented in the 110 plane. (c) High-resolution image (HR-TEM) of a TiO ${ }_{2}$ - $\mathrm{B}$ platelet-like structure calcined at $500^{\circ} \mathrm{C}$. (d) Calculated interplanar distances. (e) Electron diffraction (SAED). (f) Illustration of the simulated $1 \mathrm{D}-\mathrm{TiO}{ }_{2}-\mathrm{B}$ nanostructure.

chamber and the nanostructures synthesised by the hydrothermal process at $130^{\circ} \mathrm{C}$ for 8 days. Several platelets from $100 \mathrm{~nm}$ up to a maximum of 2 microns of thickness are shown, whose lengths vary from $500 \mathrm{~nm}$ up to several microns. The dark field image is oriented in the 110 plane of hydrogen titanate (Figure 3(b)). Figure 3(c) corresponds to an HRTEM image of a $1 \mathrm{D}-\mathrm{TiO}_{2}-\mathrm{B} 58 \mathrm{~nm}$ in diameter displaying a layered structure indicating that the rod grew along the (010) direction of $\mathrm{TiO}_{2}-\mathrm{B}$ (Figure 3(d)) with an interplanar spacing of about $0.616 \mathrm{~nm}$, a value consistent with previous reports [17]. The crystalline structure of the nanoplatelets and nanowires belongs to the family of titanium dioxides with monoclinic phase with the parameters $a=1.216 \mathrm{~nm}$, $b=0.374 \mathrm{~nm}, c=0.651 \mathrm{~nm}$, and $\beta=107.29^{\circ}$ which allows classifying this compound into the space group C2/m [3]. The rod in Figure 3(d) exhibits a set of intershell spaces, with distances of 0.376 and $0.325 \mathrm{~nm}$, corresponding to interplanar distances along the (111) and (133) directions of $1 \mathrm{D}-\mathrm{TiO}_{2}-\mathrm{B}$, respectively. The spots of the selected area electron diffraction (SAED) can be interpreted as caused by the three different crystalline orientations (Figure 3(e)). The uniform diameter and contrast of the wires are properties indicative of single crystal structures [18]. A simulation of the atomic structure of $1 \mathrm{D}-\mathrm{TiO}_{2}-\mathrm{B}$ in Figure 3(f) is shown.
3.3. X-Ray Diffraction and Raman Spectroscopy Analyses. Diffractograms and Raman spectroscopy analyses of the as-prepared and calcined at $500^{\circ} \mathrm{C}$ samples are shown in Figure 4. X-ray diffraction analysis pattern shows that crystallization of the samples varied due to the heat treatment. $\mathrm{TiO}_{2}-$ $\mathrm{B}$ phase was formed after $500^{\circ} \mathrm{C}$ calcination for hydrothermal process for 6th day (Figure 4(a)). After a revision of XRD database patterns and available literature, unidentified peaks were labelled as titanate phase $(\mathrm{T})$. For these peaks it was not possible to associate any known structure. As-prepared sample showed a high presence of water molecules in the entire diffraction pattern. Anatase (A) and titanate (T) phases showed a low presence of peaks. Samples annealed at $500^{\circ} \mathrm{C}$ clearly show how the crystalline structures change dramatically after the heat treatment. This change mainly occurred due to the water evaporation and the heating exposure time that helped to generate the structural changes that create the $\mathrm{B}$ phase of $\mathrm{TiO}_{2}$ and also eliminate the presence of impurities. No organic contaminants were found. Comparing both XRD patterns, certain anatase and titanate peaks (see grey bar in Figure 4(a)) have a predominant behaviour in the two obtained patterns. Observed anatase phase present in both patterns helped to generate B phase peaks after sample calcination. On the other hand, some of 


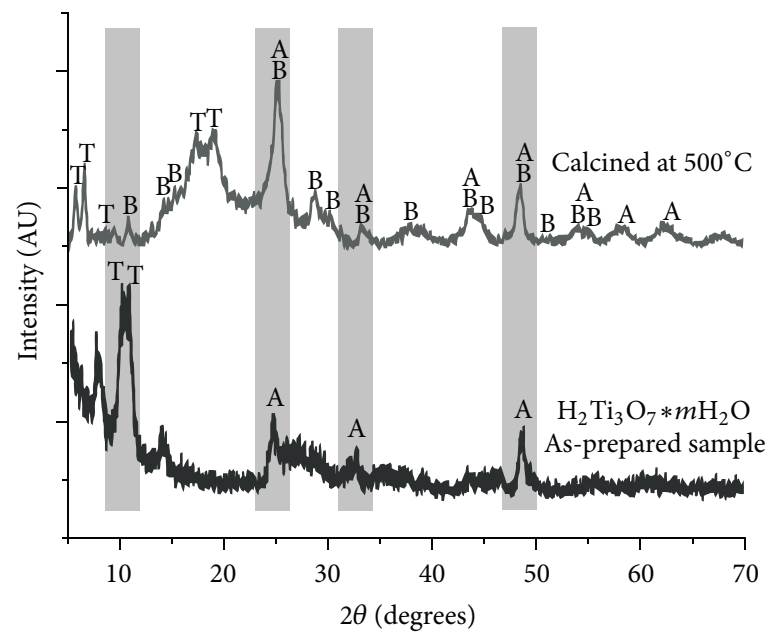

A: anatase

B: $\mathrm{TiO}_{2}-\mathrm{B}$

$\mathrm{T}$ : titanate

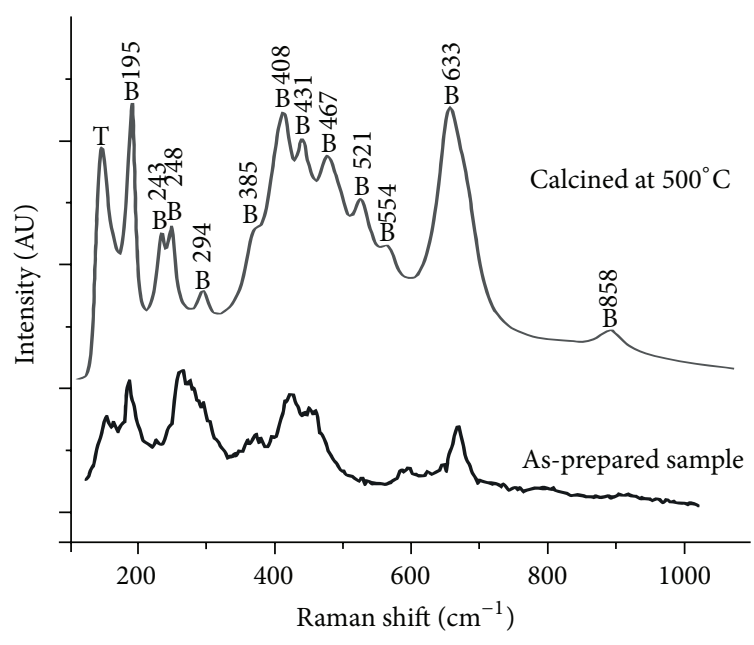

(b)

Figure 4: One-dimensional $\mathrm{TiO}_{2}-\mathrm{B}$ monocrystal phase of the nanostructures is confirmed by calcination. (a) X-ray diffraction of the sample treated at $130^{\circ} \mathrm{C}$ for 6 days and calcined at $500^{\circ} \mathrm{C}$. Peaks conformed by anatase, $\mathrm{TiO}_{2}-\mathrm{B}$, and titanate phases are shown. Patterns obtained from previous publications [5, 21]. (b) Raman spectroscopy of a sample prepared with the same hydrothermal method. Spectrum obtained for $1 \mathrm{D}-\mathrm{TiO}_{2}-\mathrm{B}$, characterized according to the relative wavelength where Raman effect was produced. Results compared with previous reports [21]. Excitation wavelength of $632.8 \mathrm{~nm}$ and $5 \mathrm{~mW}$ laser power.

the titanate peaks observed close to the 10 degrees in the as-synthetized spectrum changed its structure after the heat treatment generating $\mathrm{B}$ phase of $\mathrm{TiO}_{2}$. To characterize the observed pattern, comparison of results with previous reports was performed. Up to the $90 \%$ of similarity of the patterns was found and the remaining $10 \%$ did not match with lower intensity peaks shown in the literature guide [4, 19-21].

The confirmation of the synthesis of $\mathrm{TiO}_{2}-\mathrm{B}$ crystal structure by Raman spectroscopy spectra is shown in Figure 4(b). This result confirms the characterization obtained by XRD and shows typical peaks well defined of the sample after calcination. Moreover, titanates bands do not correspond to rutile, anatase, or brookite phase. Calcined samples at $500^{\circ} \mathrm{C}$ show similar main peaks patterns localized at 195, 248, 408, 633 , and $858 \mathrm{~cm}^{-1}$ as is described by Kolen'ko et al. in their experiment with $\mathrm{TiO}_{2}-\mathrm{B}$ nanorods [21].

3.4. Antibacterial Test. Diverse approaches of $\mathrm{TiO}_{2}$-based antibacterial nanomaterials are broadening nowadays [22], including polymers [23] and particle mixtures [24]. In specific, $1 \mathrm{D}-\mathrm{TiO}_{2}-\mathrm{B}$ structures have been tested in Klebsiella pneumoniae [25]. However, the rise of Escherichia coli multiresistant strains is a growing worldwide concern [26], and confirmed antibacterial behaviour of new materials is needed.

To address an application of $1 \mathrm{D}^{-} \mathrm{TiO}_{2-} \mathrm{B}$ material, a bacterial-growth control performance was tested (Figure 5). UV-illuminated Petri dishes clearly showed decreased colonies after treatment. Quickly, differences are noticed in $\mathrm{UV}+\mathrm{TiO}_{2}-\mathrm{B}$ at 10 minutes. Controls in dark did not result in a significant loss of viability (Figure 5(a)). Quantification of the colony forming units (CFU) of E. coli showed reduction of viable cells when they are in contact with $\mathrm{TiO}_{2}-\mathrm{B}$ and anatase and/or UV-illuminated. However, UV $+\mathrm{TiO}_{2}-\mathrm{B}$ produced a faster CFU decay than UV + anatase or UV only. (Figure 5(b)). Statistics of normalized data demonstrated that 10-minute incubation showed the most significant differences among conditions (Figure 5(c)). Less substantial differences, in all late UV-illuminated samples, were noticed. Clearly, normalized CFU data showed the best reduction slope under $\mathrm{UV}+\mathrm{TiO}_{2}-\mathrm{B}$ treatment (Figure 5(c)). One-way analysis of variance confirms slope differences between $\mathrm{UV}+\mathrm{TiO}_{2}-\mathrm{B}$ and $\mathrm{UV}$ only with a $p$ value $<0.0001$ at 10 minutes. Results for sets on dark $\mathrm{TiO}_{2}-\mathrm{B}$ showed small initial reduction viability at 10 minutes but remain constant later indicating no toxicity of nanostructures, confirming that antibacterial process only occurs driven by photocatalysis (Figures 5(a), 5(b), and 5(c)). Results for loss of viability test for anatase nanoparticles are similar to previous reports [13]. The specific role of free radical in the model presented here remains unclear, which could be addressed in further research.

Finally, the properties of $\mathrm{TiO}_{2}-\mathrm{B}$ nanostructures after testing were evaluated by Raman spectroscopy (Figure 5(d)). Nanowires were analysed before and after antibacterial experiences, where those Raman spectra did not change substantially. Furthermore, photocatalytic properties appear at the same wavelength $(303 \mathrm{~nm})$ (data not shown). Results obtained confirm that the structural and optical properties of the $\mathrm{TiO}_{2}-\mathrm{B}$ nanowires synthesised did not change after being tested for antibacterial activity. 

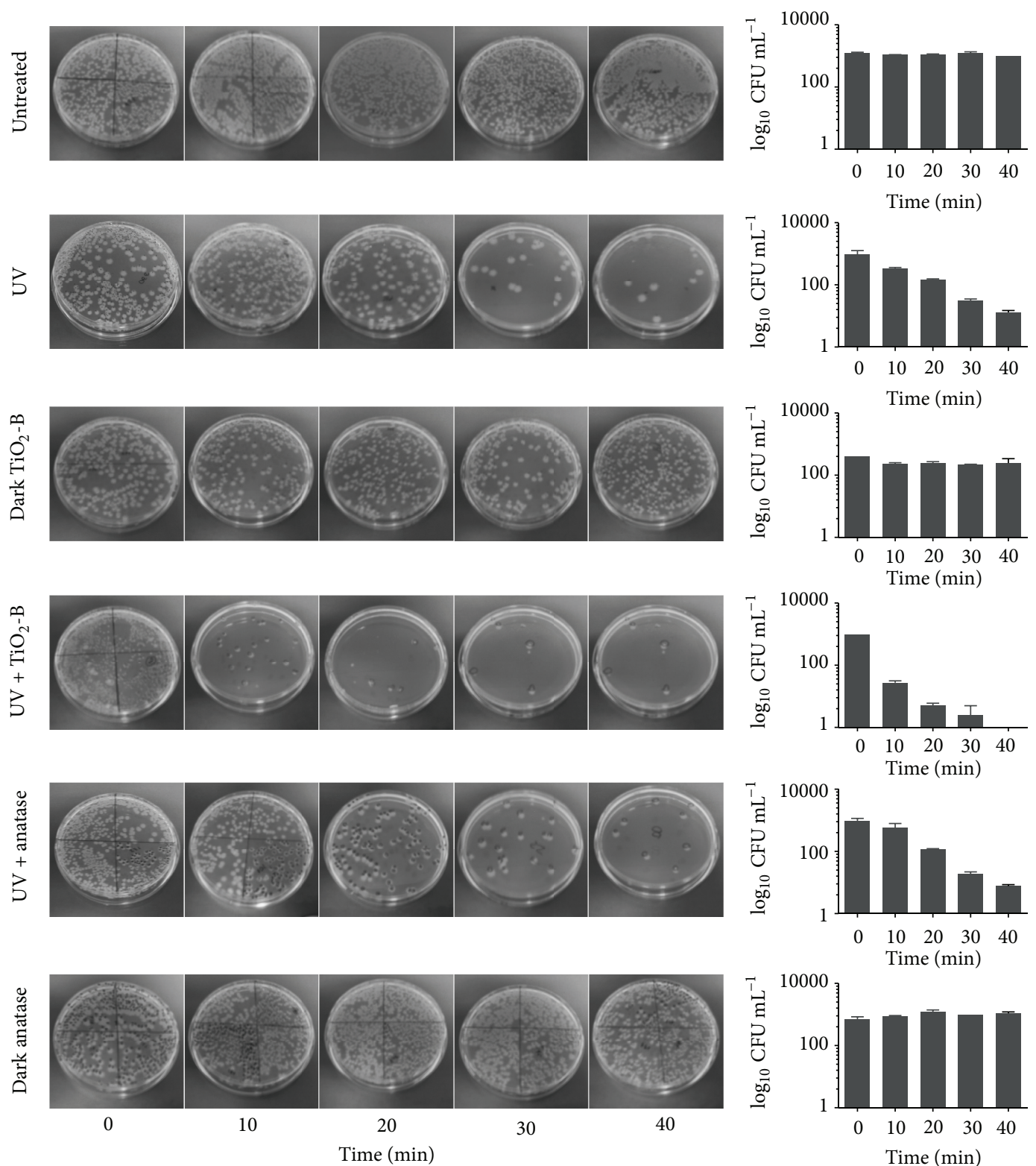

(a)

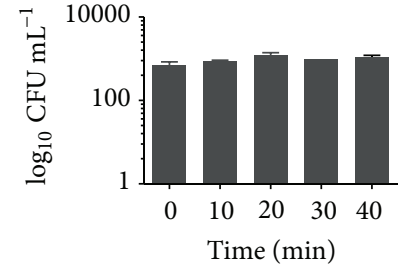

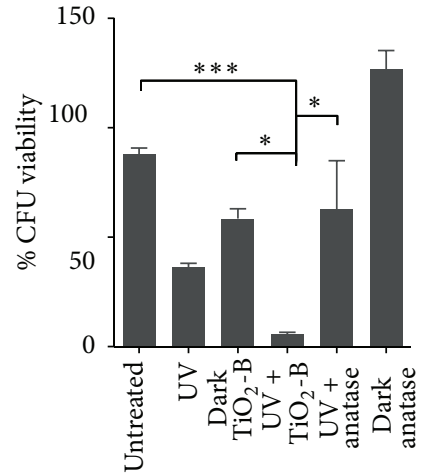

(c)

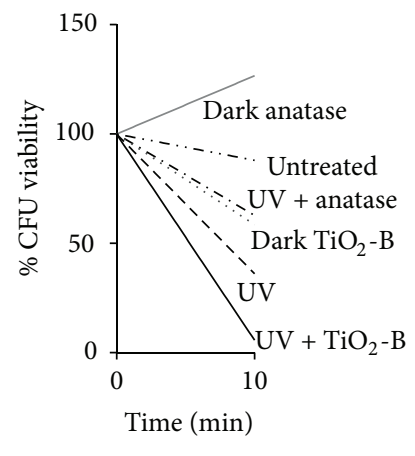

(d)

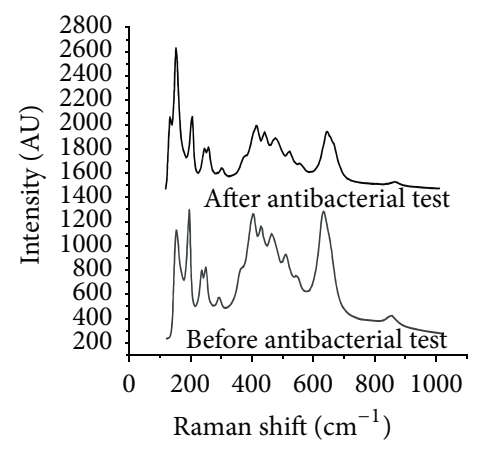

(e)

FIgure 5: Antibacterial effect of one-dimensional $\mathrm{TiO}_{2}$-B. (a) Effect of titanium compounds onto Escherichia coli colonies. Representative Petri dishes photographs of the antibacterial testing. (b) Colonies forming units (CFU) calculations per mL of initial media logarithmic graphs of each condition tested. (c) Normalized values of E. coli CFU viability at 10 minutes of incubation. One-way ANOVA and Tukey's multiple comparisons test $\left({ }^{*} p<0.05,{ }^{* * *} p<0.001\right)$. (d) Slope of the normalized CFU viability of each condition tested calculated at 10 minutes of treatment. (e) Raman spectra of one-dimensional $\mathrm{TiO}_{2}-\mathrm{B}$ before and after 60 minutes of antibacterial test. Excitation wavelength of $632.8 \mathrm{~nm}$ and $5 \mathrm{~mW}$ laser power. 


\section{Conclusions}

This work reports the successful synthesis of titanium dioxide- $\mathrm{B}$ nanowires and platelets starting from a hydrothermal process with pure $\mathrm{TiO}_{2}$ and $\mathrm{NaOH}$ at concentrations of $10 \mathrm{M}$. The as-prepared samples exhibited the titanate phase. These samples were calcined at $500^{\circ} \mathrm{C}$ and presented the monoclinic phase of titanium dioxide. Main properties of the $\mathrm{TiO}_{2}-\mathrm{B}$ platelets and nanowires were characterized utilizing a battery of analytical techniques such as XRD, Raman spectroscopy, AFM, SEM, HRTEM, and EDX analysis, and light absorption tests. These studies indicated that annealed samples presented diffraction patterns and vibration modes corresponding to the titanium dioxide indexed as the monoclinic phase. The XRD study indicated in addition the presence of anatase and titanate phases in low concentration. Features of these nanostructures go from $25 \mathrm{~nm}$ to $218 \mathrm{~nm}$ in diameter, with a mean of $102.8 \mathrm{~nm}$, and from $200 \mathrm{~nm}$ up to 2.6 micrometers in length, with a mean of $0.85 \mu \mathrm{m}$.

In this paper, we propose $1 \mathrm{D}-\mathrm{TiO}_{2}-\mathrm{B}$ as an antimicrobial material against Escherichia coli. In our case, the inherited action of free radicals produced by $\mathrm{UV}-\mathrm{TiO}_{2}-\mathrm{B}$ on the bacterial surface remains unclear. This synergic effect of reactive species needs further research at molecular level, comparing with other pathogens, under different light doses and also other $\mathrm{TiO}_{2}$ polymorphs. This report also demonstrates the optical and structural stability of $1 \mathrm{D}-\mathrm{TiO}_{2}-\mathrm{B}$ under high energy light, offering potential long-term bactericide applications especially in surface sterilization.

\section{Competing Interests}

The authors have declared that there are no competing interests.

\section{Authors' Contributions}

Sergio León-Ríos, Rodrigo Espinoza González, Sandra Fuentes, Emigdio Chávez Ángel, and Alex Echeverría performed all experimental procedures. Sergio León-Ríos, Rodrigo Espinoza González, Alex Echeverría, and Antonio E. Serrano analysed the data. Sergio León-Ríos, Alex Echeverría, Antonio E. Serrano, Cecilia S. Demergasso, and R. Antonio Zárate wrote the paper and participated in all discussions.

\section{Acknowledgments}

This work has been partially financed by Fundación Andes grant under Contract no. C-13876, FONDECYT grant under Contract no. 1080401, Anillo ACT1204, and FIC-R 2015: "Transferencia Desarrollo de Nanotransistores Basados en Cables Bacterianos del Desierto," Cod. BIP 30412822-0. This work was supported by the DGIP of the Universidad Católica del Norte. Special thanks are due to Laboratorio de Microscopia Electrónica (LME) at Laboratorio Nacional de Luz del Sincrotron (LNLS), Campinas, Brazil, for providing access to the FEG-SEM and HR-TEM. The authors thank the FCFM,
Universidad de Chile, for the use of their XRD facility. They also thank Mr. Jaime Llanos, of the Laboratorio Inorgánica, Departamento de Ciencias Químicas y Farmacéuticas, Facultad de Ciencias, UCN.

\section{References}

[1] V. Swamy, J. D. Gale, and L. S. Dubrovinsky, "Atomistic simulation of the crystal structures and bulk moduli of $\mathrm{TiO}_{2}$ polymorphs," Journal of Physics and Chemistry of Solids, vol. 62, no. 5, pp. 887-895, 2001.

[2] R. A. Zárate, S. Fuentes, J. P. Wiff, V. M. Fuenzalida, and A. L. Cabrera, "Chemical composition and phase identification of sodium titanate nanostructures grown from titania by hydrothermal processing," Journal of Physics and Chemistry of Solids, vol. 68, no. 4, pp. 628-637, 2007.

[3] R. Marchand, L. Brohan, and M. Tournoux, " $\mathrm{TiO}_{2}(\mathrm{~B})$ a new form of titanium dioxide and the potassium octatitanate $\mathrm{K}_{2} \mathrm{Ti}_{8} \mathrm{O}_{17}$, Materials Research Bulletin, vol. 15, no. 8, pp. 11291133,1980 .

[4] M. Yoshimura, W. L. Suchanek, and K. Byrappa, "Soft solution processing: a strategy for one-step processing of advanced inorganic materials," MRS Bulletin, vol. 25, no. 9, pp. 17-25, 2000.

[5] M. Kobayashi, V. V. Petrykin, M. Kakihana, K. Tomita, and M. Yoshimura, "One-step synthesis of $\mathrm{TiO}_{2}(\mathrm{~B})$ nanoparticles from a water-soluble titanium complex," Chemistry of Materials, vol. 19, no. 22, pp. 5373-5376, 2007.

[6] T. Verdier, M. Coutand, A. Bertron, and C. Roques, "Antibacterial activity of $\mathrm{TiO}_{2}$ photocatalyst alone or in coatings on E. coli: the influence of methodological aspects," Coatings, vol. 4, no. 3, pp. 670-686, 2014.

[7] K. Sunada, T. Watanabe, and K. Hashimoto, "Studies on photokilling of bacteria on $\mathrm{TiO}_{2}$ thin film," Journal of Photochemistry and Photobiology A: Chemistry, vol. 156, no. 1-3, pp. 227233, 2003.

[8] O. Carp, C. L. Huisman, and A. Reller, "Photoinduced reactivity of titanium dioxide," Progress in Solid State Chemistry, vol. 32, no. 1-2, pp. 33-177, 2004.

[9] N. A. Trunina, M. E. Darvin, K. Kordás et al., "Monitoring of $\mathrm{TiO}_{2}$ and $\mathrm{ZnO}$ nanoparticle penetration into enamel and dentine of human tooth IN VITRO and assessment of their photocatalytic ability," IEEE Journal of Selected Topics in Quantum Electronics, vol. 20, no. 3, pp. 133-140, 2014.

[10] A. Kubacka, M. S. Diez, D. Rojo et al., "Understanding the antimicrobial mechanism of $\mathrm{TiO}_{2}$-based nanocomposite films in a pathogenic bacterium," Scientific Reports, vol. 4, article 4134, 2014.

[11] J. Kiwi and V. Nadtochenko, "Evidence for the mechanism of photocatalytic degradation of the bacterial wall membrane at the $\mathrm{TiO}_{2}$ interface by ATR-FTIR and laser kinetic spectroscopy," Langmuir, vol. 21, no. 10, pp. 4631-4641, 2005.

[12] H. A. Foster, I. B. Ditta, S. Varghese, and A. Steele, "Photocatalytic disinfection using titanium dioxide: spectrum and mechanism of antimicrobial activity," Applied Microbiology and Biotechnology, vol. 90, no. 6, pp. 1847-1868, 2011.

[13] I. A. Kartsonakis, P. Liatsi, I. Danilidis, D. Bouzarelou, and G. Kordas, "Synthesis, characterization and antibacterial action of hollow titania spheres," Journal of Physics and Chemistry of Solids, vol. 69, no. 1, pp. 214-221, 2008. 
[14] X. Wang, Z. Li, J. Shi, and Y. Yu, "One-dimensional titanium dioxide nanomaterials: nanowires, nanorods, and nanobelts," Chemical Reviews, vol. 114, no. 19, pp. 9346-9384, 2014.

[15] D. Yang, H. Liu, Z. Zheng et al., "An efficient photocatalyst structure: $\mathrm{TiO}_{2}(\mathrm{~B})$ nanofibers with a shell of anatase nanocrystals," Journal of the American Chemical Society, vol. 131, no. 49, pp. 17885-17893, 2009.

[16] A. R. Armstrong, G. Armstrong, J. Canales, and P. G. Bruce, " $\mathrm{TiO}_{2}-\mathrm{B}$ nanowires," Angewandte Chemie-International Edition, vol. 43, no. 17, pp. 2286-2288, 2004.

[17] B. Zhao, F. Chen, H. Liu, and J. Zhang, "Mesoporous $\mathrm{TiO}_{2}$ B nanowires synthesized from tetrabutyl titanate," Journal of Physics and Chemistry of Solids, vol. 72, no. 3, pp. 201-206, 2011.

[18] Y. Wu, J. Xiang, C. Yang, W. Lu, and C. M. Lieber, "Singlecrystal metallic nanowires and metal/semiconductor nanowire heterostructures," Nature, vol. 430, no. 6995, pp. 61-65, 2004.

[19] G. H. Du, Q. Chen, R. C. Che, Z. Y. Yuan, and L.-M. Peng, "Preparation and structure analysis of titanium oxide nanotubes," Applied Physics Letters, vol. 79, article 3702, 2001.

[20] V. Štengl, S. Bakardjieva, J. Šubrt et al., "Sodium titanate nanorods: preparation, microstructure characterization and photocatalytic activity," Applied Catalysis B: Environmental, vol. 63, no. 1-2, pp. 20-30, 2006.

[21] Y. V. Kolen'ko, K. A. Kovnir, A. I. Gavrilov et al., "Hydrothermal synthesis and characterization of nanorods of various titanates and titanium dioxide," Journal of Physical Chemistry B, vol. 110, no. 9, pp. 4030-4038, 2006.

[22] A. Sarkar, A. Shchukarev, A.-R. Leino et al., "Photocatalytic activity of $\mathrm{TiO}_{2}$ nanoparticles: effect of thermal annealing under various gaseous atmospheres," Nanotechnology, vol. 23, no. 47, Article ID 475711, 2012.

[23] H. Kong, J. Song, and J. Jang, "Photocatalytic antibacterial capabilities of $\mathrm{TiO}_{2}$-biocidal polymer nanocomposites synthesized by a surface-initiated photopolymerization," Environmental Science and Technology, vol. 44, no. 14, pp. 5672-5676, 2010.

[24] T. Asahara, H. Koseki, T. Tsurumoto et al., "The bactericidal efficacy of a photocatalytic $\mathrm{TiO}_{2}$ particle mixture with oxidizer against Staphylococcus aureus," Japanese Journal of Infectious Diseases, vol. 62, no. 5, pp. 378-380, 2009.

[25] L. Korösi, D. Dömötör, S. Beke et al., "Antibacterial activity of nanocrystalline $\mathrm{TiO}_{2}(\mathrm{~B})$ on multiresistant Klebsiella pneumoniae strains," Science of Advanced Materials, vol. 5, no. 9, pp. 1184-1192, 2013.

[26] J. D. Pitout and K. B. Laupland, "Extended-spectrum $\beta$ lactamase-producing Enterobacteriaceae: an emerging publichealth concern," The Lancet Infectious Diseases, vol. 8, no. 3, pp. 159-166, 2008. 

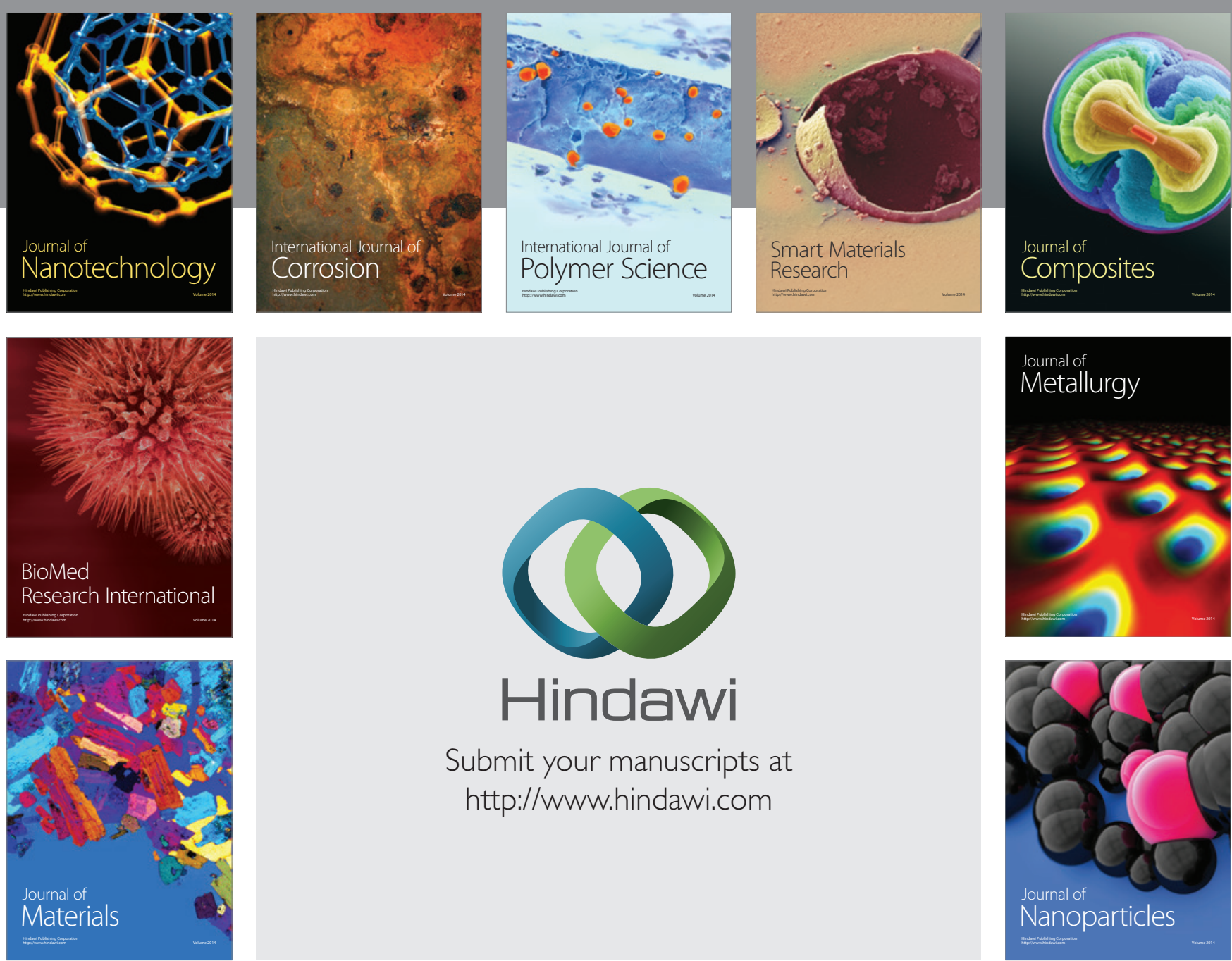

\section{Hindawi}

Submit your manuscripts at

http://www.hindawi.com



Materials Science and Engineering
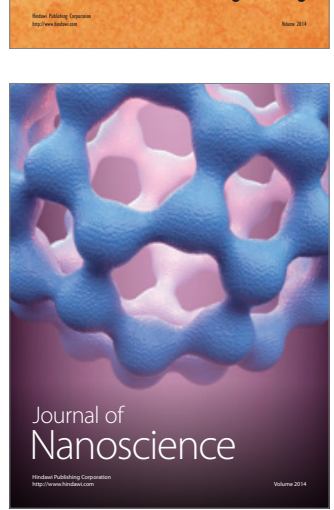
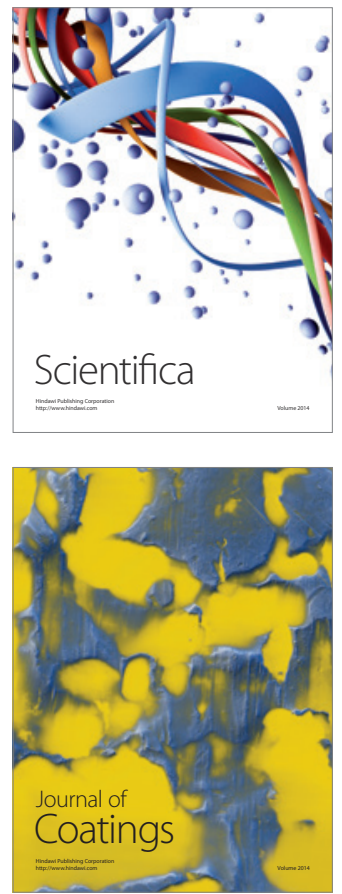
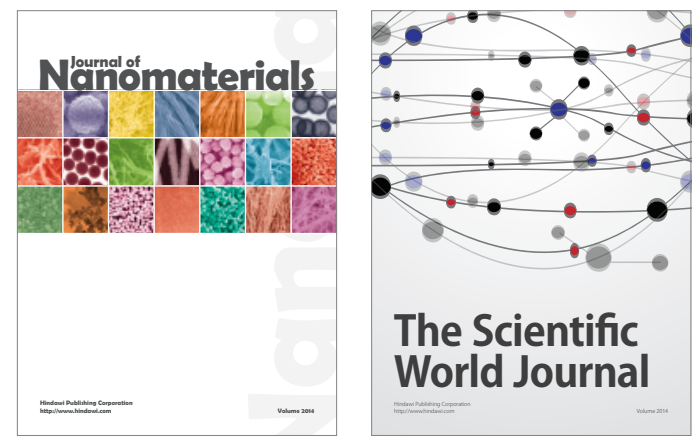

The Scientific World Journal
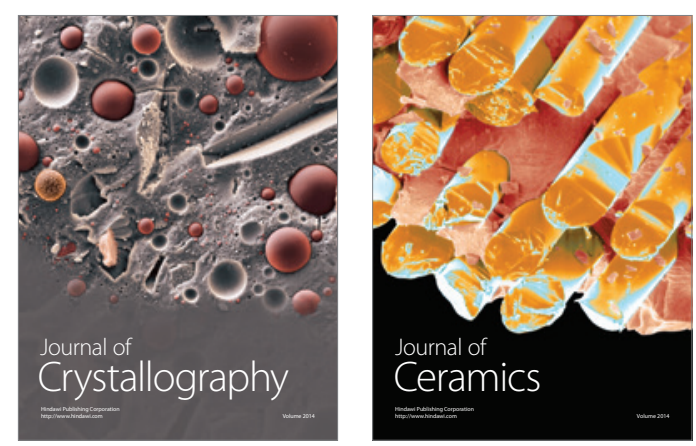
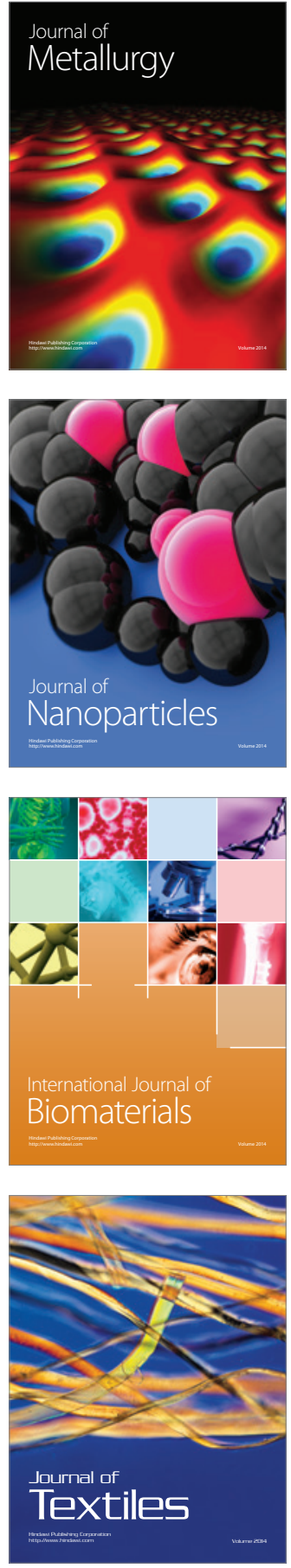